\title{
High fat diet enhances cardiac abnormalities in SHR rats: Protective role of heme oxygenase- adiponectin axis
}

\author{
Jian $\mathrm{Cao}^{1 \dagger}{ }^{1 \dagger}$ Komal Sodhi ${ }^{2 \dagger}$, Nitin Puri ${ }^{2}$, Sumit R Monu ${ }^{2}$, Rita Rezzani ${ }^{3}$ and Nader G Abraham ${ }^{2 *}$
}

\begin{abstract}
Background: High dietary fat intake is a major risk factor for development of cardiovascular and metabolic dysfunction including obesity, cardiomyopathy and hypertension.

Methods: The present study was designed to examine effect of high fat (HF) diet on cardio-vascular structure and function in spontaneously hypertensive rats (SHR), fed HF diet for 15 weeks, a phenotype designed to mimic metabolic syndrome.

Results: Development of metabolic syndrome like phenotype was confirmed using parameters, including body weight, total cholesterol and blood pressure levels. High fat diet impaired vascular relaxation by acetylcholine and exacerbated cardiac dysfunction in SHRs as evidenced by lower left ventricular function, and higher coronary resistance $(C R)$ as compared to controls $(p<0.05)$. The histological examination revealed significant myocardial and peri-vascular fibrosis in hearts from SHRs on HF diet. This cardiac dysfunction was associated with increased levels of inflammatory cytokines, COX-2, NOX-2, TxB2 expression and increase in superoxide $\left(\mathrm{O}_{2}{ }^{-}\right)$levels in SHR fed a HF diet $(p<0.05)$. HO-1 induction via cobalt-protoporphyrin (COPP, $3 \mathrm{mg} / \mathrm{kg})$, in HF fed rats, not only improved cardiac performance parameters, but also prevented myocardial and perivascular fibrosis. These effects of CoPP were accompanied by enhanced levels of cardiac adiponectin levels, PAMPK, peNOS and iNOS expression; otherwise significantly attenuated $(p<0.05)$ in HF fed SHRs. Prevention of such beneficial effects of CoPP by the concurrent administration of the $\mathrm{HO}$ inhibitor stannic mesoporphyrin (SnMP) corroborates the role of $\mathrm{HO}$ system in mediating such effects.
\end{abstract}

Conclusion: In conclusion, this novel study demonstrates that up-regulation of HO-1 improves cardiac and vascular dysfunction by blunting oxidative stress, COX-2 levels and increasing adiponectin levels in hypertensive rats on HF diet.

Keywords: heme oxygenase, adiponectin, high fat diet, COX-2, oxidative stress

\section{Background}

Obesity and hypertension are two major risk factors that lead to increased incidence of cardiac diseases including coronary artery disease, heart failure and cardiomyopathy [1-3]. Blood pressure, which strongly correlates with body mass index, is one of the most important determinants of cardiovascular function [4]. In addition, obesity

\footnotetext{
* Correspondence: nader.abraham@utoledo.edu

+ Contributed equally

${ }^{2}$ Department of Physiology and Pharmacology, College of Medicine,

University of Toledo, Toledo, Ohio, 43614, USA

Full list of author information is available at the end of the article
}

also leads to abnormal cardiac function through mechanisms that are independent of hypertension $[5,6]$. Metabolic syndrome is a clinico-pathological condition which entails superimposition of these abnormalities and is characterized by systemic inflammation and oxidative stress [3,7] A combination of these risk factors leads to disruption of metabolic homeostasis and may further contribute towards progressive cardiovascular dysfunction.

The heme-HO system, comprising of $\mathrm{HO}-1$ (inducible) and HO-2 (constitutive) isoforms, is one of the key defense mechanisms against oxidative stress [8]. This 
effect of $\mathrm{HO}$ system is attributable, in large part, to the antioxidant and anti-apoptotic properties of the heme degradation products, bilirubin/biliverdin and carbon monoxide (CO) [9]. Previous studies have shown that upregulation of $\mathrm{HO}-1$ exerts a cardio protective effect in hypertensive rats [10-14] by reducing myocardial hypertrophy, oxidative stress and inflammation. Over expression of HO-1 is also known to cause adipose tissue remodeling by increasing adiponectin in obese and nonobese diabetic rats and mice [15-18] along with obesity associated suppression of inflammatory cytokines. Adiponectin is an adipose tissue-specific protein that has been shown to have antiatherogenic, antihypertensive and insulin-sensitizing properties [19-21]. An inverse relationship exists between plasma adiponectin levels and systolic blood pressure as well as vascular dysfunction in obese subjects and animals [19,22]. HO-1 functions as a stress response/chaperone protein and increases adiponectin levels which may cause activation of AMPK-AKT signaling [23-25], which contributes to improved NO bioavailability, vascular function, glucose transport and fatty acid oxidation [26,27]. Thus, alterations in the heme-HO system not only influence vascular function but also modulate metabolic and cardiovascular processes which, in turn, are dependent upon activation of adiponectin/AMPK pathways.

The beneficial role of HO enzyme system in animal models of obesity and hypertension are clearly defined but paucity of evidence exists regarding similar effects in co-morbid conditions such as hypertension and obesity. In light of this evidence, the aim of this novel study was to explore the potential effect of HO-1 induction in spontaneously hypertensive rats (SHR) fed a high fat diet, a phenotype designed to mimic metabolic syndrome. We tested our hypothesis by using a well-described high fat regimen [28] that does not cause atherosclerotic lesion formation in mice [29], to address the effects of a known HO-1 inducer, cobalt protoporphyrin (CoPP). To verify that the effects of CoPP were due to an increase in $\mathrm{HO}$-activity, we also treated a group of SHR concurrently with stannous mesoporphyrin (SnMP) to inhibit HO activity. Our results show that obesity exacerbates myocardial and vascular damage in SHRs, and $\mathrm{HO}-1$ induction improves heart function in parallel with increased adiponectin levels and reduced expression of myocardial pro-inflammatory enzymes such as COX-2 and iNOS. Thus, HO-1 appears to play a critical role in the cellular defense against obesity-induced cardiovascular dysfunction in a hypertensive animal model fed a high fat diet. These findings may have important clinical implications in the management of patients with metabolic syndrome.

\section{Methods}

\section{Animal treatment}

All animal studies were approved by the New York Medical College Animal Care and Use Committee in accordance with the National Institutes of Health Guidelines for Care and Use of Laboratory Animals. Fifty-eight seven-week-old male SHRs were purchased from Charles River Laboratories and were divided into four groups: A) SHR control, B) SHR-fat, C) SHR-fat and CoPP treatment, D) SHR-fat and CoPP and SnMP treatment. SHR rats were fed ad libitum either with a normal diet (group A) containing 11\% fat, 62\% carbohydrate, and $27.0 \%$ protein total, $12.6 \mathrm{KJ} / \mathrm{g}$ or a high fat diet (groups B, C, D) containing $58 \%$ fat from lard, $25.6 \%$ carbohydrate, and $16.4 \%$ protein yielding $23.4 \mathrm{KJ} /$ g (Bio-SERV, Frenchtown, NJ) for 15 weeks [28,30]. The diet used is distinct from the so-called "Western" or "atherosclerotic" diet which contains, in addition to high fat, cholesterol and bile acids. While the high fat diet used in the present study results in obesity, it does not cause atherosclerotic lesion formation in mice [29]. After 4 weeks of high fat diet, cobalt protoporphyrin (CoPP), an inducer of HO-1, was administered intraperitoneally once a week $(3 \mathrm{mg} / \mathrm{kg})$ for 11 weeks to SHR rats maintained on a high fat diet. Some of the SHR treated with CoPP were concurrently treated with tin mesoporphyrin IX dichloride (SnMP), to inhibit HO activity, which was administered intraperitoneally three times a week $(20 \mathrm{mg} / \mathrm{kg})$ [11] to ascertain that any effects of CoPP treatment were related to increased $\mathrm{HO}$ activity. The untreated SHR rats maintained on the high fat diet were administered the vehicle for CoPP and SnMP once a week and 3 times a week respectively (0.1 $\mathrm{mM}$ sodium citrate buffer $\mathrm{pH} 7.8$ ) for 11 weeks.

Rats were weighed every 7 days and systolic blood pressure was determined weekly by the tail-cuff method.

After a 6-hour fast, rats were anesthetized with sodium pentobarbital ( $65 \mathrm{mg} / \mathrm{kg}$, i.p.) and blood was obtained from a tail vein for glucose measurement using a glucometer (Lifescan Inc., Miligitas, CA). Blood samples were then collected and stored as previously described [15].

\section{Isolated Heart Preparation}

Three days after the last CoPP (or vehicle) injection, rats were anaesthetized with pentobarbital, i.p., and heparinized via the left femoral vein $(250$ units $/ \mathrm{kg}$ ). The heart was rapidly excised, placed in cold perfusion medium and weighed. The isolated hearts were attached to the Langerdorff apparatus and retrogradely perfused (at $37^{\circ}$ C) using constant perfusion pressure of $80 \mathrm{~cm} \mathrm{H}_{2} \mathrm{O}$, then perfusion pressure was decreased to $20 \mathrm{mmHg}$ for $30 \mathrm{~min}$, and then pressure was increased back to 80 
$\mathrm{mmHg}$ for the remaining $30 \mathrm{~min}$ (reperfusion) [29]. The perfusion medium consisted of oxygenated Krebs-Henseleit buffer [31,32]. For measurement of ventricular systolic and end diastolic pressure (EDP), latex balloons were inserted into the left ventricle of the heart through the mitral valve and connected to a Harvard pressure transducer. In each experiment EDP was set at 10 $\mathrm{mmHg}$ and kept stable during the first 10 minutes of perfusion. Coronary perfusion pressure (CPP) was monitored by a second pressure transducer connected to the aortic cannula. Left ventricular developed pressure (LVDevP), EDP, dP/dTmax and dP/dTmin were all derived or calculated from the continuous monitoring of the LV pressure signal. In all experiments, coronary flow was continuously monitored by collecting the cardiac effluent. Coronary resistance (CR) was defined as input pressure divided by coronary flow per gram of myocardial tissue (mmHgxminxg/mL). At the end of each experiment, hearts were collected, half were used for histology examination and half of them were rapidly frozen in liquid nitrogen and stored at $-80^{\circ} \mathrm{C}$.

\section{Assessment of Myocyte Cross-Sectional Area, Myocardial Fibrosis and Collagen in Myocardial Tissue}

Hearts were fixed in $10 \%$ buffered formalin, and embedded in paraffin wax and sectioned to $5 \mu \mathrm{m}$. For measurement of the cross-sectional area, 100 cells (per animal) from the left ventricular wall were randomly chosen and analyzed in hematoxylin staining. The myocyte cross-sectional area and myocardial fibrosis were quantitatively analyzed with Image Pro-Plus 4.5.1 software in digitalized microscopic images. Myocardial fibrosis in the tissue sections was quantitatively analyzed by morphometry in 2 ways: (1) on the perivascular fibrosis, and (2) on myocardial tissue (total fibrosis index). The collagen in myocardial tissue was visualized by Sirius Red staining under polarization microscopy and then quantified.

\section{Assessment of Vascular Reactivity}

The aorta was removed, cleaned of fat and loose connective tissue, placed in cold Krebs-bicarbonate solution, and sectioned into 3-mm-long rings. Vasorelaxation responses of phenylephrine-constricted arteries to cumulative increments in acetylcholine $\left(10^{-9}\right.$ to $10^{-4}$ $\mathrm{mol} / \mathrm{L}$ ) were examined in the presence of indomethacin $(10 \mu \mathrm{mol} / \mathrm{L})$ as described [33].

\section{Western Blot Analysis of Cardiac Tissue for protein expression}

At the time of sacrifice, hearts were harvested, and stored at $-140^{\circ} \mathrm{C}$. Frozen hearts were pulverized under liquid nitrogen and placed in a homogenization buffer prior to immunoblotting with antibodies against HO-1, and HO-2 (Stressgen Biotechnologies Corp., Victoria, $\mathrm{BC}), \mathrm{COX}-2$, TX synthase, NOX-2, AKT, AMPK, pAMPK(Thr172), pAKT and adiponectin (Cell Signaling Technology, Inc., Beverly, MA) and eNOS, peNOS(serine 1177), and iNOS (Santa Cruz Biotechnology, Santa Cruz, CA). Immunoblotting was performed in cardiac tissue as previously described $[15,33]$.

\section{Measurement of $\mathrm{HO}$ activity}

$\mathrm{HO}$ activity in heart tissue was assayed as described previously [15] using a technique in which bilirubin, the end product of heme degradation, was extracted with chloroform, and its concentration was determined spectrophotometrically (dual UV-visible beam spectrophotometer Lambda 25; PerkinElmer Life and Analytical Sciences, Waltham, MA) using the difference in absorbance at a wavelength from 460 to $530 \mathrm{~nm}$, with an extinction coefficient of $40 \mathrm{mM}^{-1} \mathrm{~cm}^{-1}$.

\section{Measurements of $\mathrm{O}_{2}^{-}$production and total cholesterol levels}

Total cholesterol was measured in serum using a cholesterol Quantification Kit (Biovision, Mountainview, CA) according to the manufacturer's instructions. For the detection of $\mathrm{O}_{2}^{-}$, homogenized hearts were placed in plastic scintillation vials containing $5 \mu \mathrm{mol} / \mathrm{l}$ lucigenin in a final volume of $1 \mathrm{ml}$ of air-equilibrated Krebs solution as described previously [15].

\section{Plasma Adiponectin and inflammatory cytokines Measurements}

The high molecular weight (HMW) HMW form of adiponectin, IL-6, TNF- $\alpha$ and TXB2 levels were determined using an ELISA assay (Pierce Biotechnology, Inc., Woburn, MA) as described previously [15].

\section{Statistical Analysis}

The data are presented as mean \pm standard error (SEM) where $n=6 /$ group for the results. For comparison between treatment groups, the Null hypothesis was tested by a single factor analysis of variance (ANOVA) for multiple groups or unpaired $t$-test for two groups. Statistical significance $(\mathrm{p}<0.05)$ between the experimental groups was determined by the Fisher method of analysis for multiple comparisons.

\section{Results \\ Effect of a high-fat diet on body weight and metabolic response}

Figure 1A shows the percent change in body weight over its baseline values in the 4 groups. In untreated SHR rats body weight increased $54 \% \pm 5.5$ on a normal diet over a period of 15 weeks, whereas in rats fed a high fat diet body weight increased $79 \% \pm 3.7(\mathrm{p}<0.05)$. 


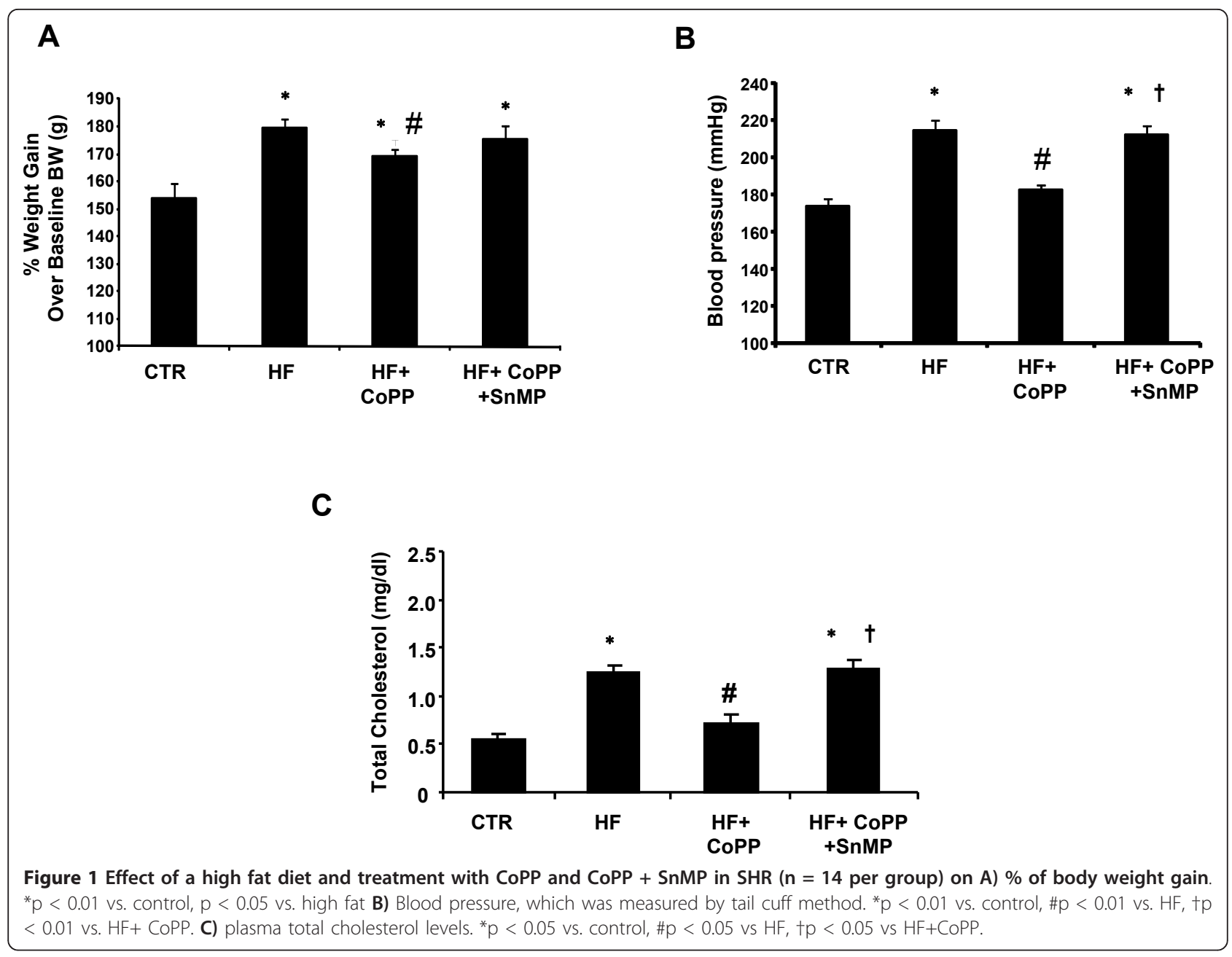

The total body weight observed after 15 weeks of study was $367 \pm 10.7 \mathrm{gms}$ in SHR controls and $419 \pm 6.3 \mathrm{gms}$ in SHR rats fed a high fat diet (data not shown). We also examined the effect of long-term CoPP treatment on body weight gain in response to a high fat diet. Weekly treatment with CoPP was started 4 weeks after the initiation of the high fat diet and was well tolerated by the SHR ( $\mathrm{n}=14$ /group); activity and grooming were maintained during CoPP treatment. Rats fed a high fat diet and concurrently exposed to CoPP, showed reduction in body weight as compared to SHR rats on high fat diet, $68 \% \pm 2.4(\mathrm{p}<0.05)$. A significant increase in body weight was seen when animals fed a high fat diet were exposed to CoPP + SnMP. The weight gain was $75 \% \pm 4.9$ and was not significantly different from animals fed a high fat diet. The total body weight observed after 15 weeks of study in rats fed a high fat diet and concurrently exposed to CoPP was $386 \pm 9.7 \mathrm{gms}$ and was increased to $416 \pm 8.1 \mathrm{gms}$ in SHR rats fed a high fat diet and treated with CoPP and SnMP (data not shown).
Systolic blood pressure was increased over the 15week period in SHR rats (Figure 1B; $n=6$ /group). The systolic blood pressure was $175 \pm 11 \mathrm{mmHg}$ in the SHR control and was significantly increased in the rats fed a high fat diet, $211 \pm 9 \mathrm{mmHg}(\mathrm{p}<0.05)$. The elevation in systolic pressure was attenuated by CoPP treatment in SHR fed a high fat diet whereas SnMP treatment nullified the antihypertensive effect of CoPP in SHR fed a high-fat diet (Figure 1B). The mean blood glucose level in the SHR rats maintained on a normal diet was $128 \pm$ $4 \mathrm{mg} / \mathrm{dl}$, and was increased to $173 \pm 14 \mathrm{mg} / \mathrm{dl}$ by a high fat diet ( $p<0.05 ; \mathrm{n}=6 /$ group) (data not shown). This increase in blood glucose levels was significantly attenuated by CoPP treatment in SHR rats fed a high fat diet $(137 \pm 4.5 \mathrm{mg} / \mathrm{dl})$ and this effect was reversed by treatment with SnMP $(180 \pm 7.8 \mathrm{mg} / \mathrm{dl})$ (data not shown).

Plasma cholesterol levels remained elevated in SHRs fed a high-fat diet as compared to their controls. Plasma cholesterol levels were $0.55 \pm 0.11$ in SHRs fed a normal diet for 15 weeks, and levels were increased to $1.25 \pm$ $0.15 \mathrm{mg} / \mathrm{dL}$ by 15 weeks on the high-fat $\operatorname{diet}(P<0.05)$ 
(Figure 1C). CoPP treatment prevented the increase in cholesterol levels in SHR while concomitant treatment with SnMP blocked the effect of CoPP.

\section{Effect of high fat diet on cardiac parameters}

The collagen III was higher in hearts of SHRs fed a high fat diet $(P<0.05)$ when compared to untreated animals (Figure 2A). The perivascular fibrosis index was higher in SHRs fed a high fat diet than those animals fed a normal diet $(P<0.05)$ (Figure $2 \mathrm{~B})$. CoPP administration prevented the occurrence of these increases in animals fed a high fat diet on perivascular fibrosis while concurrent administration of SnMP did not significantly reversed the effect of $\mathrm{CoPP}$ (Figure $2 \mathrm{~B}$ ). The myocyte cross-sectional area was increased by a high fat diet in SHRs. CoPP treatment prevented the increase in myocyte cross-sectional area while concurrent administration of SnMP did not significantly reversed the effect of CoPP (Figure 2C).

\section{Effect of high fat diet on CR and cardiac function during ischemia/reperfusion}

Our results show that during low perfusion pressure (i.e. ischemia), $C R$ increased over baseline values in all groups, but CR in SHR mice was significantly higher than in controls $(\mathrm{p}<0.05)$ (Figure $3 \mathrm{~A})$. This phenomenon, defined as 'paradoxical vasoconstriction', has been described previously by our group in both control and diabetic animals [34]. CoPP modulated coronary tone during the ischemic period significantly reducing vasoconstriction. After $30 \mathrm{~min}$ of reperfusion, CR was still significantly increased over baseline values in high fat hearts $(\mathrm{p}<0.05)$, while CR in High fat CoPP group returned to baseline values (Figure $3 \mathrm{~A})$. The CoPP-
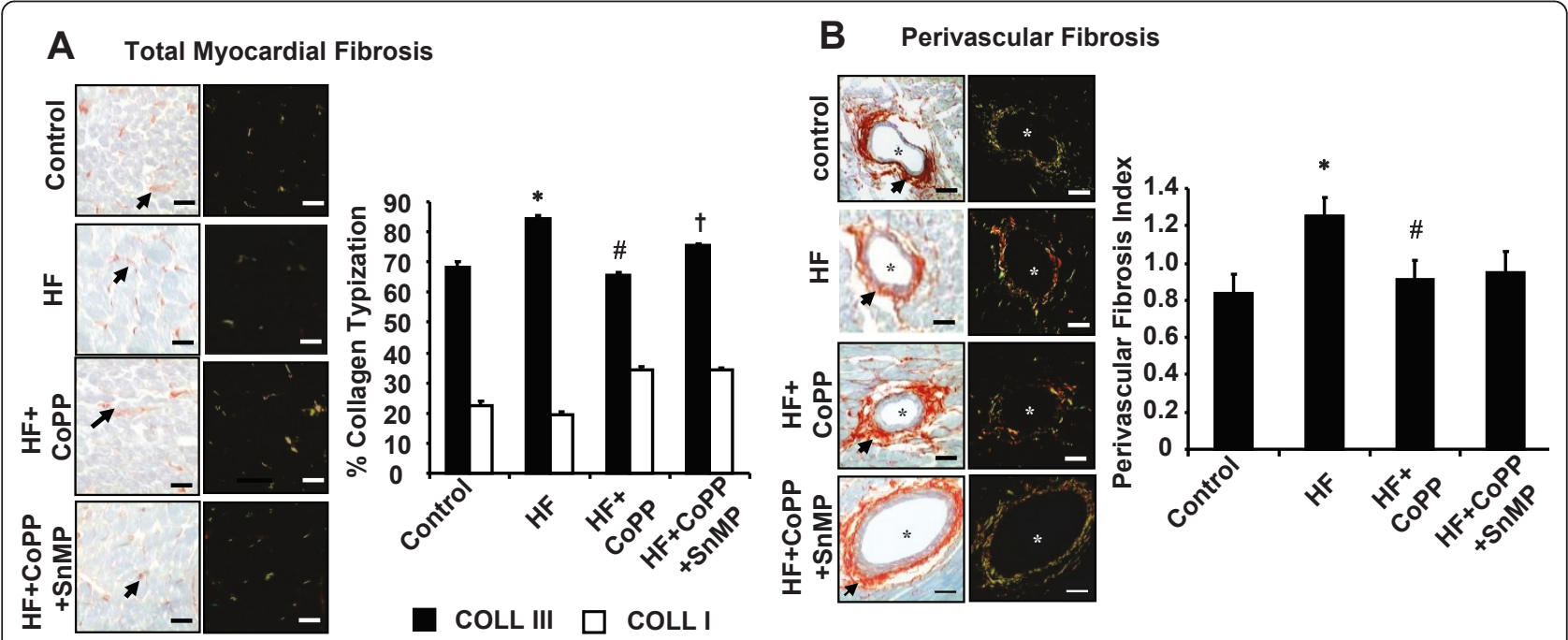

C

Myocyte Cross-sectional Area
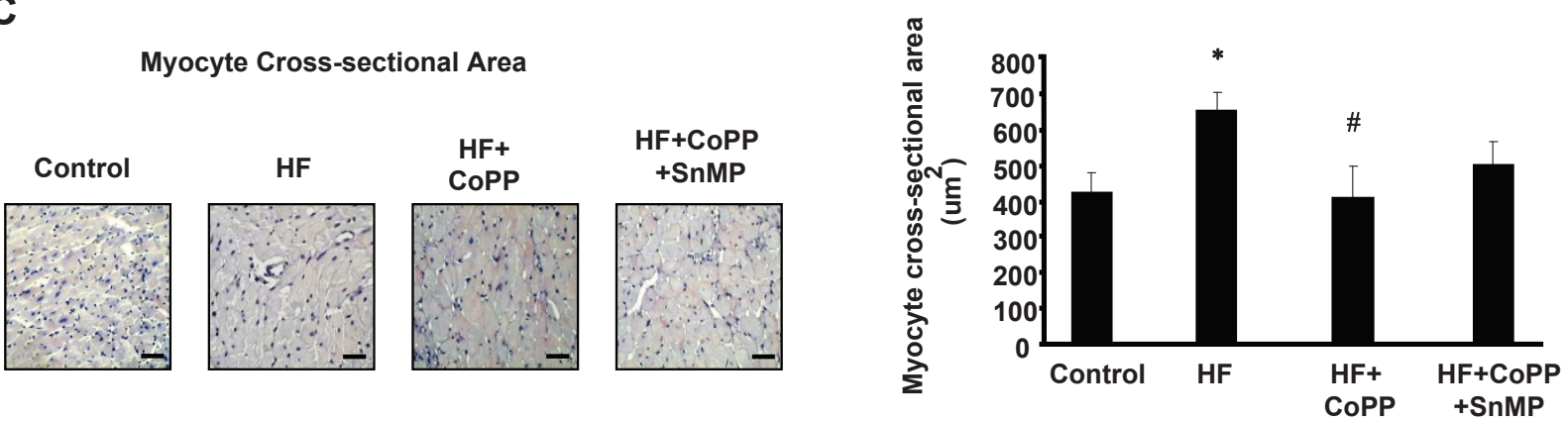

Figure 2 Histology change of the heart. A) Total myocardial fibrosis. Transverse section of left ventricle stained with Sirius Red and observed under light and polarized microscope. Whole collagen is red stained and indicated by arrows. Type I collagen is green-yellow, while Type III collagen is orange-red. Bar. 50 um. * $p<0.01$ vs. control, $p<0.05$ vs. HF, $+p<0.05$ vs HF+ CoPP B) Perivascular fibrosis. Transverse sections of intramuscular arteries with perivascular fibrosis stained with Sirius Red and observed under light and polarized microscope. Bar. $100 \mu \mathrm{m}$. ${ }^{*} \mathrm{p}<$ 0.01 vs. control, \#p < 0.05 vs.HF. C) Myocyte cross-sectional area. Left ventricular myocyte cross-sectional areas stained with hematoxylin. The myocyte cross-sectional area and myocardial fibrosis were quantitatively analyzed with Image Pro-Plus 4.5.1 software in digitalized microscopic images. For measurement of the cross-sectional area, 100 cells (per animal) from the left ventricular wall were randomly chosen and analyzed in hematoxylin staining. Bar. $50 \mu \mathrm{m} .{ }^{*} \mathrm{p}<0.01$ vs. control, \#p $<0.05$ vs. HF. 


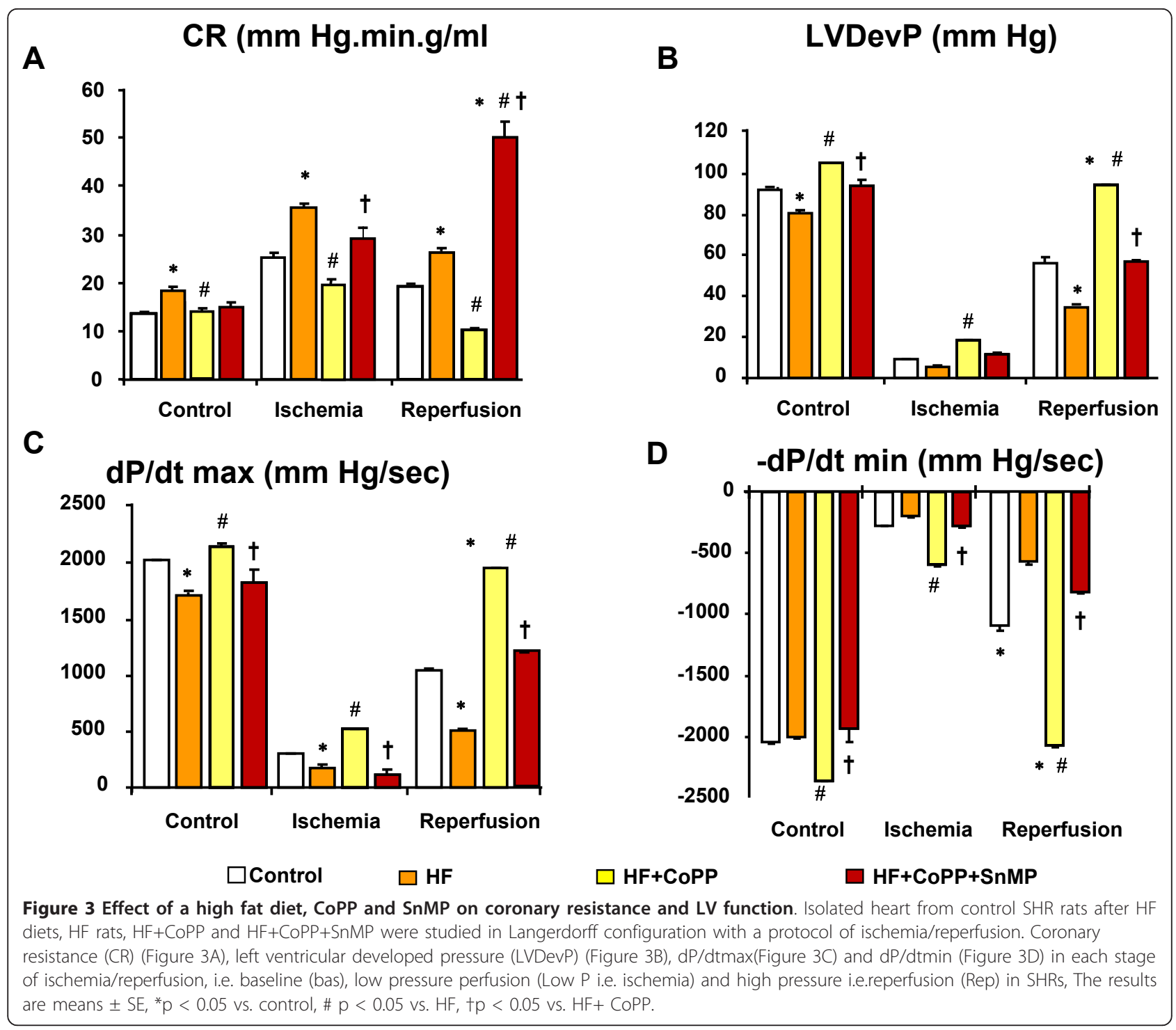

"normalization" of coronary tone at reperfusion in HF hearts was mirrored by better overall cardiac function during both low pressure ischemia and reperfusion times. Indeed, LVDevP (Figure 3B), dP/dtmax (Figure $3 \mathrm{C}$ ) and $\mathrm{dP} / \mathrm{dtmin}$ (Figure $3 \mathrm{D}$ ) were all significantly improved compared to the untreated group $(\mathrm{p}<0.05)$.

Effect of high fat diet on Vascular Reactivity and superoxide levels

Aortic endothelial dilatory responses to acetylcholine (at concentration of $10^{-5}$ and $10^{-4} \mathrm{mmol} / \mathrm{L}$ respectively) were significantly impaired in SHRs after 15 weeks of a high-fat diet compared with those fed a normal diet $(P$ $<0.05$ ) (Figure 4A). Endothelial function was improved in SHRs as a result of the CoPP treatment $(P<0.05)$, but exacerbated by SnMP (Figure 4A) indicating that it is specifically the endothelial dilatory response that is impaired by a high fat diet in this animal model. Cardiac oxidative stress was increased as cortical superoxide generation was greater in SHR fed a high fat diet compared with rats fed a normal diet (Figure 4B where $n=$ 6/group), ( $<<0.05)$. CoPP treatment prevented the increase in cardiac $\mathrm{O}_{2}{ }^{-}$generation in SHR maintained on a high fat diet $(\mathrm{p}<0.01)$, an effect abolished by concurrent administration of SnMP.

Effect of high fat diet on plasma adiponectin, inflammatory cytokines and TxB2 Levels

Plasma IL-6 and TNF- $\alpha$ (Figure 5A and 5B) levels were greater in SHR fed a high fat diet compared to rats fed a normal diet ( $\mathrm{n}=6 /$ group), $(\mathrm{p}<0.05)$. Increasing HO-1 by CoPP administration significantly decreased plasma cytokines and this effect was prevented by concurrent SnMP treatment $(\mathrm{p}<0.01$, Figure $5 \mathrm{~A}$ and $5 \mathrm{~B})$. Similar 
A

\section{Vascular relaxation to acetylcholine}

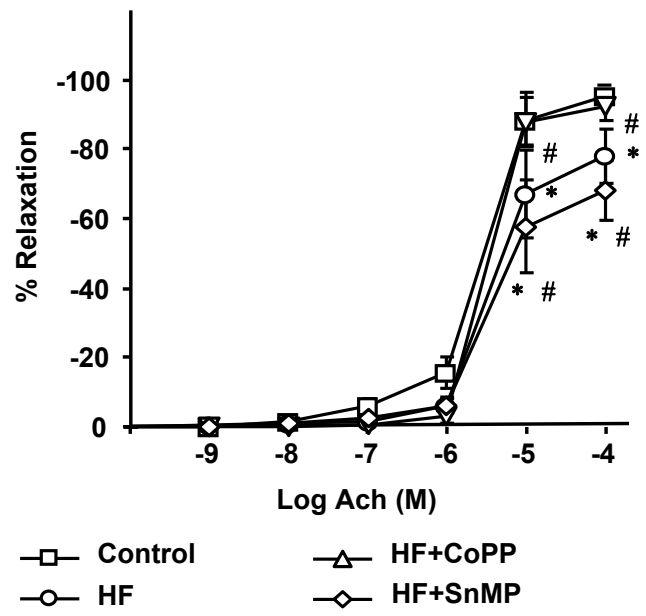

B

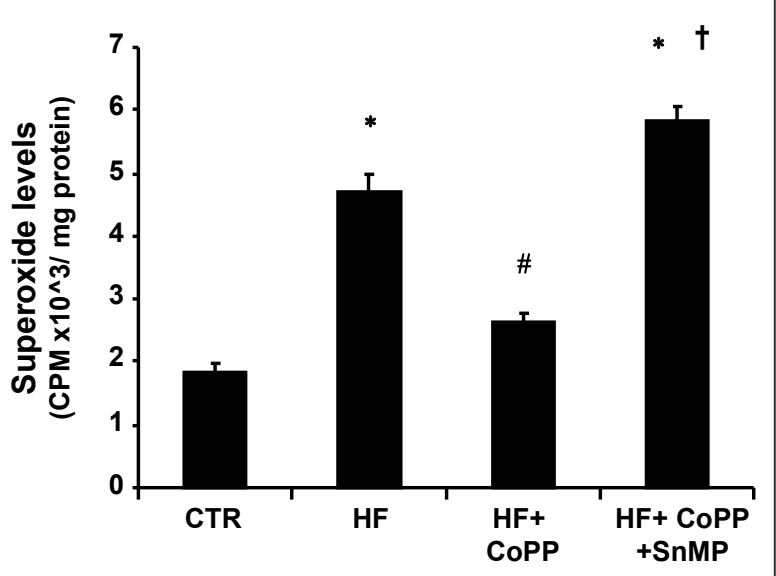

Figure 4 Effect of a high fat diet, CoPP and SnMP on A) vascular reactivity in SHR rats. Aorta was precontracted with phenylephrine (PE) and then exposed to acetylcholine (Ach) in a dose dependent manner $\left(10^{-9}-10^{-4} \mathrm{M}\right) .{ }^{*} \mathrm{p}<0.05 \mathrm{vs}$. control, \#p $<0.05$ vs. HF+ CoPP. B) Superoxide production. ${ }^{*} p<0.01$ vs. control, \# $p<0.01$ vs. HF, † $p<0.01$ vs. HF+ CoPP.

pattern was observed in plasma TxB2 levels as shown in Figure $5 \mathrm{C}$ ( $\mathrm{n}=6 /$ group), $(\mathrm{p}<0.05)$. Plasma adiponectin levels were lower in rats fed a high fat diet when compared to control animals fed a normal diet $(\mathrm{p}<0.05$; $\mathrm{n}$ $=6$ /group) (Figure 5D). This effect was reversed when rats were treated with CoPP $(\mathrm{p}<0.05)$. Indeed, in SHR rats maintained on a high-fat diet and treated with CoPP, plasma adiponectin levels were higher than those in the respective control groups $(\mathrm{p}<0.05)$. Concurrent administration of SnMP with CoPP in the SHR fed a high fat diet prevented the increase in adiponectin, so that the levels of this protein were not different from those in the untreated SHR.

\section{Effect of high fat diet on Cardiac COX-2, TXA2 and NOX-2 Levels}

Hearts isolated from SHRs fed a high fat diet showed a significant increase in markers of oxidative stress compared to animals fed a normal diet ( $\mathrm{p}<0.05$, respectively) (Figures 6A, B and 6C). Treatment with CoPP resulted in a decrease in COX-2, TxA2 and NOX-2 expression in SHRs fed a high fat diet ( $\mathrm{p}<0.01$ respectively), an effect abolished by concurrent administration of SnMP.

\section{Effect of high fat diet on cardiac HO-1}

First, we confirmed that CoPP treatment for 11 weeks resulted in up-regulation of $\mathrm{HO}-1$. $\mathrm{HO}-1$ protein in the hearts of SHR fed a high fat diet was significantly less than that of the respective control group (Figure 7A where $n=6$ /group) when the latter was fed a normal $\operatorname{diet}(\mathrm{p}<0.05)$. Treatment with CoPP resulted in a significant increase in HO-1 levels in SHR fed a high-fat diet. Although SnMP treatment showed a significant increase in $\mathrm{HO}-1$ expression (Figure 7A), it is a potent inhibitor of $\mathrm{HO}$ activity as shown previously [11,35] and thus prevents heme degradation and inhibits formation of $\mathrm{CO}$ and biliverdin. $\mathrm{HO}-2$ levels were unaffected either by high fat diet or by CoPP treatment (Figure 7A). Consistent with protein expression, $\mathrm{HO}$ activity was significantly decreased in obese SHR hearts compared to the control group (Figure 7B). CoPP treatment significantly increased $\mathrm{HO}$ activity in SHR fed a high fat diet, $1.45 \pm$ $0.20 \mathrm{nmol}$ bilirubin $/ \mathrm{mg} / \mathrm{hr}$ compared to $0.39+0.09 \mathrm{nmol}$ bilirubin/mg/hr in untreated SHR fed a high fat diet ( $\mathrm{p}$ $<0.001)$. The concurrent administration of SnMP resulted in significant decrease of $\mathrm{HO}$ activity as shown in Figure 7B.

Effect of high fat diet on Cardiac adiponectin, pAMPK and pAKT Expression

Cardiac adiponectin levels, normalized against $\beta$-actin, exhibited a similar pattern to plasma adiponectin levels. Thus, feeding SHR a high fat diet for 15 weeks resulted in a decrease in adiponectin compared to untreated SHR (Figure $8 ; n=6$ /group). Induction of $\mathrm{HO}-1$ with CoPP increased cardiac adiponectin levels in hypertensive rats $(\mathrm{p}<0.01)$ and the increase in SHR was prevented and reversed to a decrease when the rats were, also, treated with SnMP to inhibit HO activity (Figure 
A

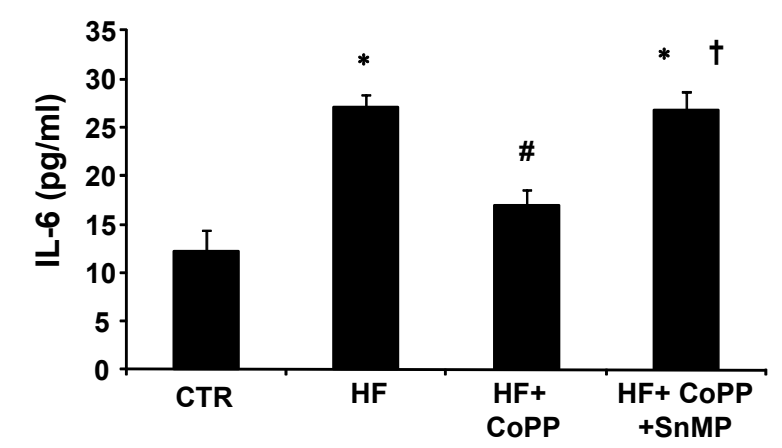

C

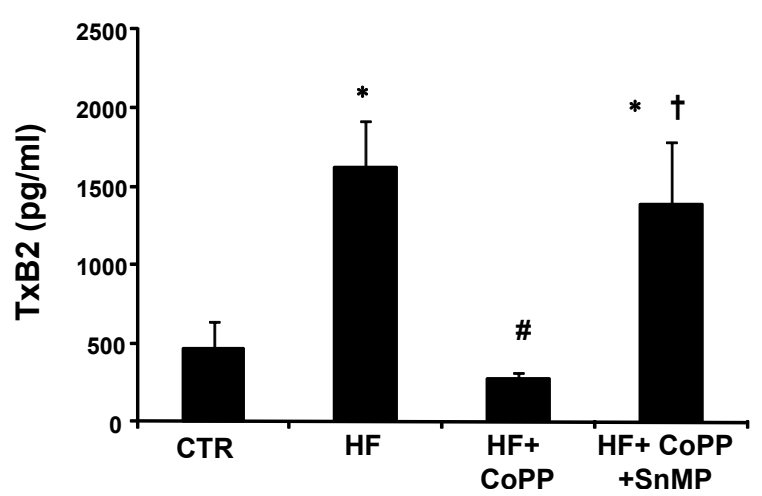

B

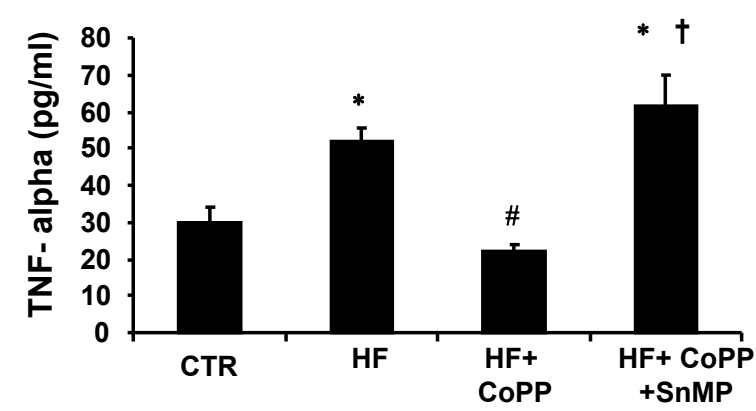

D

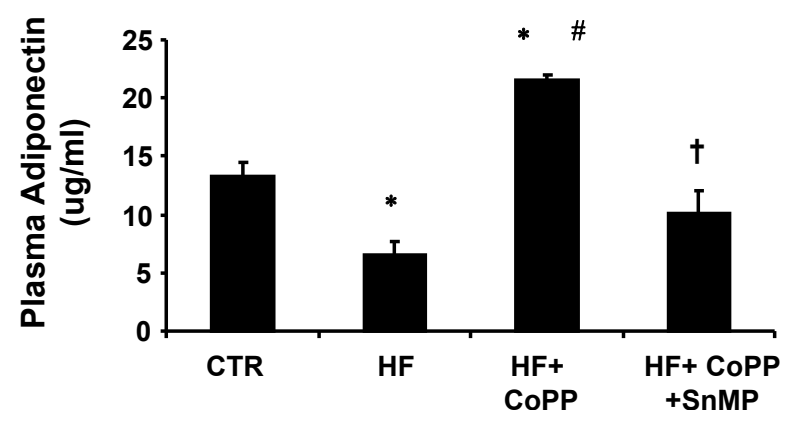

Figure 5 Effect of a high fat diet, CoPP and SnMP on plasma cytokines, TXB2 and adiponectin levels in SHR animals. $n=6$ for each group. A) Plasma IL-6 levels. * $p<0.01$ vs. control, \# $p<0.01$ vs. HF, † $p<0.01$ vs. HF+ CoPP. B) TNF- $\alpha$ levels. ${ }^{*} p<0.05$ vs. control, \#p $<0.05$ vs. HF, $\uparrow p<0.05$ vs. HF+ CoPP. C) TxB2 levels. ${ }^{*} p<0.05$ vs. control, \#p $<0.05$ vs. HF, $\dagger p<0.05$ vs. HF+ CoPP. D) adiponectin levels. ${ }^{*} p<0.05$ vs. control, \#p $<0.05$ vs. HF, $† p<0.05$ vs. HF+ CoPP.

8). A high fat diet resulted in significant decreases in pAMPK and pAKT expression in hearts from SHR ( $\mathrm{p}<$ $0.05 ; \mathrm{n}=6 /$ group) (Figure 8 ). CoPP administration caused a significant increase in the expression of pAKT and $\mathrm{pAMPK}$ in the rats fed a high fat diet $(\mathrm{p}<0.05)$ compared to untreated rats fed a high fat diet. The changes in expression of pAMPK and pAKT paralleled those seen with HO-1 protein expression. In SHR maintained on a high fat diet and treated with CoPP, the concurrent administration of SnMP prevented the increase in pAKT and pAMPK; indeed, the expression of both pAKT and PAMPK was reduced to levels lower than those seen in SHR on the high fat diet alone $(\mathrm{p}<$ $0.01)$.

Effect of high fat diet on Cardiac eNOS, peNOS and iNOS Levels

Compared to animals fed a normal diet, SHR animals fed a high fat diet exhibited lower levels of eNOS and peNOS protein $(\mathrm{p}<0.05)$ (Figure 8) CoPP administration produced an enhanced expression of eNOS and
peNOS protein ( $\mathrm{p}<0.05$ compared to untreated animals) in SHRs fed a high fat diet (Figure 8). In contrast, SnMP administration resulted in eNOS and peNOS protein in SHRs fed a high fat diet (Figure 8). Hearts isolated from SHRs fed a high fat diet showed a significant increase in iNOS expression compared to animals fed a normal diet ( $\mathrm{p}<0.05$, respectively) (Figures 8 ). Treatment with CoPP resulted in a decrease in iNOS in SHRs fed a high fat diet ( $\mathrm{p}<0.0$, Figure 8). In contrast, SnMP did not prevent the increase of iNOS expression in SHRs fed a high fat diet (Figures 8).

\section{Discussion}

The results of the present study demonstrate that SHR fed a high fat diet develop patho-physiological abnormalities similar to that observed in metabolic syndrome. This phenotype is characterized by increased levels of body weight, blood cholesterol and blood pressure along with an accelerated decline in cardiac function when compared to SHR maintained on a normal diet. We, also, demonstrated that cardiac $\mathrm{HO}-1$ induction, 


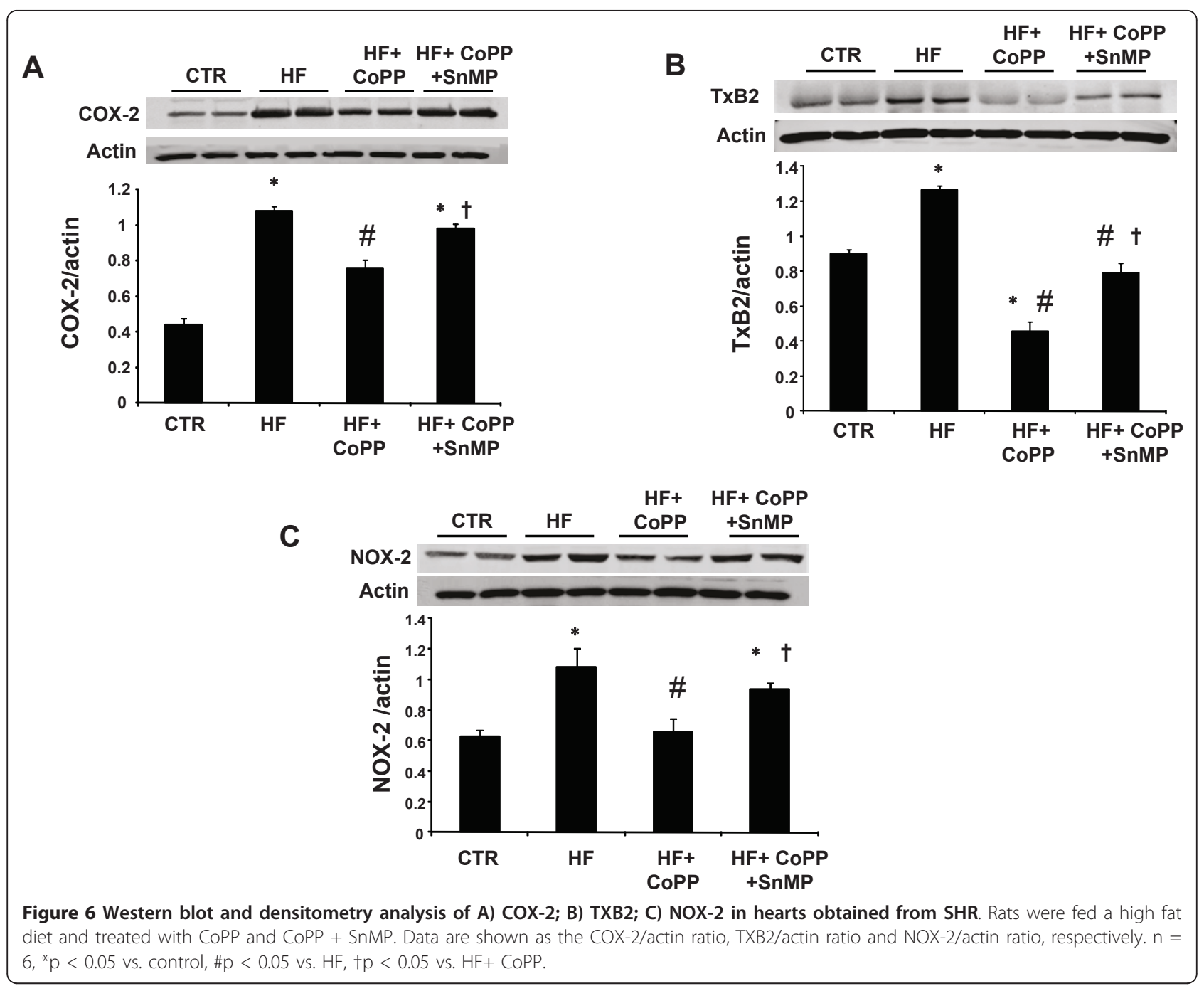

accompanied by increased plasma and tissue adiponectin levels, resulted in the improvement of cardiovascular function as manifested by a decrease in blood pressure, coronary resistance (CR), myocardial fibrosis; and increase in left ventricular function and vascular relaxation, as compared to control. The upregulation of HO-1 was associated with a concomitant decrease in the levels of $\mathrm{O}_{2}{ }^{-}, \mathrm{COX}-2$ and iNOS, markers of oxidative stress. Furthermore, there was a decrease in cardiac remodeling, and an increase in the expression of cardiac pAKT, pAMPK and peNOS via induction of $\mathrm{HO}-1$-adiponectin axis. To the best of our knowledge, this is the first report showing a protective effect of $\mathrm{HO}$-adiponectin axis in a co-morbid condition where a pre-existing cardio-vascular pathology is further aggravated by addition of a HF diet.

High fat intake increased body weight, serum cholesterol and blood pressure in SHR and these changes in metabolic indices were associated with cardiovascular dysfunction in these animals. Previous studies have shown that HO-1 induction decreases obesity, reduces levels of visceral and subcutaneous fat and normalizes the metabolic profile in obese rats and mice $[15,17,36,37]$. Also HO-1 overexpression is known to improve cardiovascular dysfunction in hypertensive rats $[7,11]$. In contrast, in the current study we induced a metabolic syndrome-like phenotype in hypertensive animals. SHR demonstrate chronic hypertension, oxidative stress and cardiac damage [38]. All of these parameters were worsened by the addition of high fat diet, strengthening our hypothesis that obesity and the associated metabolic abnormalities accelerate pathological preexisting cardiovascular changes. Reversal of these pathophysiological abnormalities by $\mathrm{HO}-1$-adiponectin induction corroborates the protective effects of the heme-oxygenase system in such a setting.

Metabolic syndrome-mediated increases in oxidative stress contribute to cardiovascular dysfunction via 


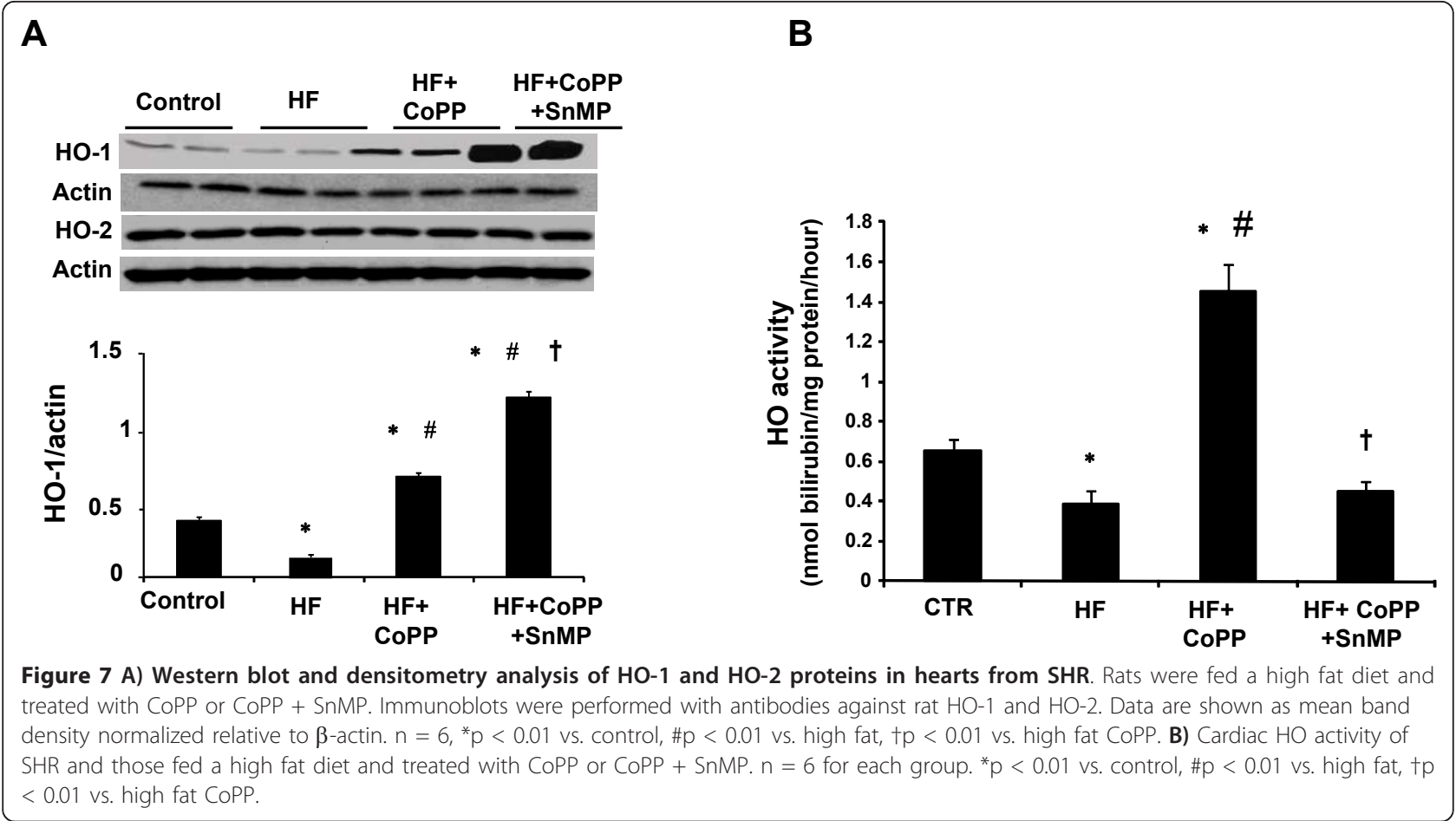

endothelial cell sloughing and beta cell apoptosis [39]. Sustained increases in $\mathrm{O}_{2}^{-}$levels and cytokines, including TNF- $\alpha$ and its receptor, lead to monocyte phenotype transition, myocytic apoptosis, and activation of matrix metalloproteinase. This, in turn, modifies the interstitial matrix, augmenting further ventricular remodeling $[40,41]$. COX-2 is considered a pro-inflammatory enzyme as free radicals and prostaglandins (PGs) are produced during its catalytic cycle [8]. It has been shown in our previous reports that upregulation of HO-1 decreases vasoconstrictors, such as cyclooxygenase (COX-2), PGs and thromboxane syntheses (TxA2) levels $[8,42]$ by regulating the cellular heme levels and ROS. The heme-HO system is a stress response system (reviewed in [8] that undergoes activation under conditions of increased oxidative stress such as those presented here. Induction of HO-1 resulted in decreased cardiac levels of superoxide and NOX-2 expression which may be due to a decrease in the levels of NADPH oxidase [43], a heme-dependent protein, and/or an increase in the levels of superoxide dismutase EC-SOD [44]. Also in the present study, increased cardiac iNOS expression and impaired vascular relaxation in rats fed a high-fat diet was reversed by $\mathrm{HO}-1$ induction which may involve the interplay of one of the various mechanisms including, $\mathrm{CO}$ generation, $\mathrm{HO}-1$-induced increase in eNOS expression and increased $\mathrm{NO}$ bioavailability due to an increase in cellular antioxidants [37,45-47].
In the present study, a decrease in coronary vascular reactivity manifested by coronary resistance, myocardial fibrosis and cardiac function was found in SHRs fed a high fat diet. The increase in expression of HO-1/adiponectin reverses these deleterious effects with a resultant improvement in energy metabolism and an amelioration of the damaged endothelial and cardiac function seen in SHRs fed a high fat diet. We studied coronary microvascular reactivity and hemodynamics in the isolated, empty, beating heart of SHRs fed a high fat diet. This was prevented in CoPP-treated animals by SnMP suggesting the seminal role of increased $\mathrm{HO}$ activity in instigating the changes attributable to increased HO-I expression. This finding highlights the role of the $\mathrm{HO}$ system in the preservation of microvascular and cardiac function.

Apart from effects on heme degradation products, HO1 up-regulation was associated with increased cardiac and plasma levels of adiponectin. This causality between $\mathrm{HO}$ activity and adiponectin release was strengthened by the inhibitory effects of SnMP on both $\mathrm{HO}$ activity and adiponectin levels. It has been recently shown that the beneficial effects of heme- HO system in established cardiovascular-metabolic disorders is mediated, at least in part, via its effect on adiponectindependent pathways $[15,48,49]$. Results presented in the current study support and advance our hypothesis that, in addition to its antioxidant properties, the heme-oxygenase system enhances the adiponectin axis which, in 


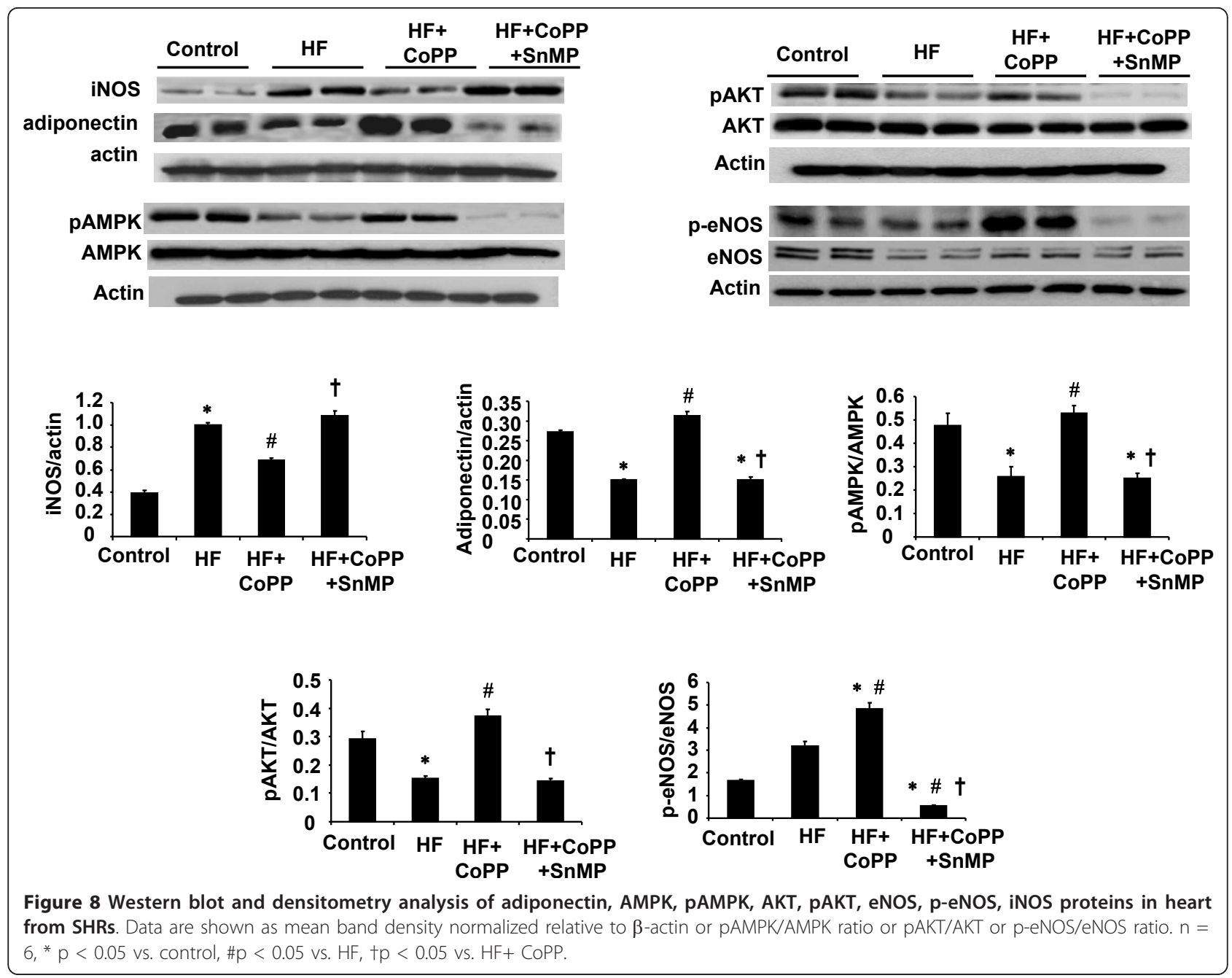

turn, modulates multiple physiological processes and may contribute towards $\mathrm{HO}$-mediated attenuation of cardiac dysfunction $[17,18,50]$.

The HO-1-mediated increase in adiponectin was associated with an increase in cardiac pAMPK-pAKT signaling and cross-talk between AMPK and AKT levels appear to correlate with $\mathrm{HO}-1$ and adiponectin levels $[16,18,25,51]$. This is of particular importance in the setting of myocardial ischemia of SHR rats fed a high fat diet due to the very-high-energy demands and lowenergy reserves of the heart. Amplifying signaling through AMPK by HO-1 induction during early reperfusion is beneficial to the injured myocardium due to the ability of AMPK to promote ATP generation $[52,53]$ and to attenuate cardiomyocyte apoptosis [54]. An increase in AMPK-AKT signaling is considered an important metabolic response that is necessary for the attenuation of ROS-mediated cardiac and endothelial dysfunction [55] and both pAMPK and pAKT use eNOS as a substrate and enhance the levels of peNOS $[8,56,57]$. The results of this study support this link as induction of HO-1-adiponectin axis, also, increased peNOS expression in the heart of SHR. The seminal role of increased HO-1 expression and $\mathrm{HO}$ activity in cardiac protection is further strengthened by the results obtained when SnMP was concurrently administered with CoPP; the inhibition of $\mathrm{HO}$ activity prevented the beneficial effects of $\mathrm{HO}-1$ induction in obese SHR with regard to blood pressure, adiponectin, pAKT and pAMPK. In summary, these observations support the beneficially role of pharmacogenetic interventions targeted towards $\mathrm{HO}-1$-adiponectin axis in patients with metabolic syndrome. Such patients often exhibit chronic energy imbalance along with a wide array of cardiovascular abnormalities amenable to aggravation by confounding factors such as diet induced obesity. Restoration of metabolic homeostasis by activation oh HO-1-adiponectin axis could not only improve the energy profile but also attenuate associated cardiovascular patho-physiological alterations observed in the patients with metabolic syndrome. 


\section{Conclusion}

In conclusion, the results of the present study demonstrate that upregulation of $\mathrm{HO}-1$ in association with increased levels of adiponectin prevents vascular and cardiac dysfunction in SHRs fed a high fat diet, a phenotype designed to mimic metabolic syndrome. The pharmacological enhancement of $\mathrm{HO}-1$ expression, resulting in a phenotype resistant to injurious stimuli, permits the heart to initiate a crucial and immediate defense against the events associated with the metabolic syndrome, thereby preventing the continued deterioration in cardiac function associated with this disease.

\section{Acknowledgements}

All authors had full access to the data and take responsibility for its integrity. All authors have read and agree with the manuscript as written. We also thank Jennifer Brown for her outstanding editorial assistance in the preparation of the manuscript.

This work was supported by NIH grants DK068134, HL55601 and HL34300 (NGA).

\section{Author details}

${ }^{1}$ Department of Geriatric Cardiology, Chinese PLA General Hospital, Beijing 100853, China. ${ }^{2}$ Department of Physiology and Pharmacology, College of Medicine, University of Toledo, Toledo, Ohio, 43614, USA. ${ }^{3}$ Department of Biomedical Science, Division of Anatomy, University of Brescia, Brescia Italy.

\section{Authors' contributions}

*JC and KS contributed equally to this work

JC drafted the manuscript. KS performed all the experiments except vascular activity. SRM did the vascular activity. RR carried out the morphological studies in heart. NGA conceived the study, and participated in its design and coordination.

All authors read and approved the final manuscript.

\section{Competing interests}

The authors declare that they have no competing interests.

Received: 11 October 2011 Accepted: 23 December 2011

Published: 23 December 2011

\section{References}

1. Zalesin KC, Franklin BA, Miller WM, Peterson ED, McCullough PA: Impact of obesity on cardiovascular disease. Med Clin North Am 2011, 95:919-937.

2. Hall JE: The kidney, hypertension, and obesity. Hypertension 2003, 41:625-633.

3. Knight SF, Quigley JE, Yuan J, Roy SS, Elmarakby A, Imig JD: Endothelial dysfunction and the development of renal injury in spontaneously hypertensive rats fed a high-fat diet. Hypertension 2008, 51:352-359.

4. Garrison RJ, Kannel WB, Stokes J, Castelli WP: Incidence and precursors of hypertension in young adults: the Framingham Offspring Study. Prev Med 1987, 16:235-251.

5. Kenchaiah S, Evans JC, Levy D, Wilson PW, Benjamin EJ, Larson MG, Kannel WB, Vasan RS: Obesity and the risk of heart failure. N Engl J Med 2002, 347:305-313

6. Mottillo S, Filion KB, Genest J, Joseph L, Pilote L, Poirier P, Rinfret S, Schiffrin EL, Eisenberg MJ: The metabolic syndrome and cardiovascular risk a systematic review and meta-analysis. J Am Coll Cardiol 2010, 56:1113-1132

7. Berg AH, Scherer PE: Adipose tissue, inflammation, and cardiovascular disease. Circ Res 2005, 96:939-949.

8. Abraham NG, Kappas A: Pharmacological and clinical aspects of heme oxygenase. Pharmacol Rev 2008, 60:79-127.
9. Wu L, Wang R: Carbon monoxide: endogenous production, physiological functions, and pharmacological applications. Pharmacol Rev 2005, 57:585-630.

10. Sacerdoti D, Escalante B, Abraham NG, McGiff JC, Levere RD, Schwartzman ML: Treatment with tin prevents the development of hypertension in spontaneously hypertensive rats. Science 1989, 243:388-390.

11. Botros FT, Schwartzman ML, Stier CT Jr, Goodman Al, Abraham NG: Increase in heme oxygenase-1 levels ameliorates renovascular hypertension. Kidney Int 2005, 68:2745-2755.

12. Sabaawy HE, Zhang F, Nguyen X, Elhosseiny A, Nasjletti A, Schwartzman M, Dennery P, Kappas A, Abraham NG: Human heme oxygenase-1 gene transfer lowers blood pressure and promotes growth in spontaneously hypertensive rats. Hypertension 2001, 38:210-215.

13. Buja LM: Myocardial ischemia and reperfusion injury. Cardiovasc Pathol 2005, 14:170-175.

14. Cao J, Inoue K, Li X, Drummond G, Abraham NG: Physiological significance of heme oxygenase in hypertension. Int J Biochem Cell Biol 2009, 41:1025-1033.

15. Li M, Kim DH, Tsenovoy PL, Peterson SJ, Rezzani R, Rodella LF, Aronow WS, Ikehara S, Abraham NG: Treatment of obese diabetic mice with a heme oxygenase inducer reduces visceral and subcutaneous adiposity, increases adiponectin levels, and improves insulin sensitivity and glucose tolerance. Diabetes 2008, 57:1526-1535.

16. Li M, Peterson S, Husney D, Inaba M, Guo K, Terada E, Morita T, Patil K, Kappas A, Ikehara S, Abraham NG: Interdiction of the diabetic state in NOD mice by sustained induction of heme oxygenase: possible role of carbon monoxide and bilirubin. Antioxid Redox Signal 2007, 9:855-863.

17. Kim DH, Burgess AP, Li M, Tsenovoy PL, Addabbo F, McClung JA, Puri N, Abraham NG: Heme oxygenase-mediated increases in adiponectin decrease fat content and inflammatory cytokines, tumor necrosis factoralpha and interleukin- 6 in Zucker rats and reduce adipogenesis in human mesenchymal stem cells. J Pharmacol Exp Ther 2008, 325:833-840

18. Nicolai A, Li M, Kim DH, Peterson SJ, Vanella L, Positano V, Gastaldelli A Rezzani R, Rodella LF, Drummond G, Kusmic C, L'Abbate A, Kappas A, Abraham NG: Heme Oxygenase-1 Induction Remodels Adipose Tissue and Improves Insulin Sensitivity in Obesity-Induced Diabetic Rats. Hypertension 2009, 53:508-515.

19. Iwasa Y, Otsubo S, Ishizuka T, Uchida K, Nitta K: Influence of serum highmolecular-weight and total adiponectin on arteriosclerosis in $\lg \mathrm{A}$ nephropathy patients. Nephron Clin Pract 2008, 108:c226-c232.

20. Huang KC, Chen CL, Chuang LM, Ho SR, Tai TY, Yang WS: Plasma adiponectin levels and blood pressures in nondiabetic adolescent females. J Clin Endocrinol Metab 2003, 88:4130-4134.

21. Iwashima $Y$, Katsuya T, Ishikawa K, Ouchi N, Ohishi M, Sugimoto K, Fu Y, Motone M, Yamamoto K, Matsuo A, Ohashi K, Kihara S, Funahashi T, Rakugi H, Matsuzawa Y, Ogihara T: Hypoadiponectinemia is an independent risk factor for hypertension. Hypertension 2004, 43:1318-1323.

22. Abraham NG, Kruger A, Peterson S: High serum levels of adiponectin in HO-1preconditioning in mice and rats with Type 2 diabetes improve vascular function. American Heart Association 2007.

23. Cao J, Drummond G, Inoue K, Sodhi K, Li XY, Omura S: Upregulation of Heme Oxygenase-1 Combined with Increased Adiponectin Lowers Blood Pressure in Diabetic Spontaneously Hypertensive Rats through a Reduction in Endothelial Cell Dysfunction, Apoptosis and Oxidative Stress. Int J Mol Sci 2008, 9:2388-2406.

24. Peterson SJ, Drummond G, Kim DH, Li M, Kruger AL, Ikehara S, Abraham NG: L-4F treatment reduces adiposity, increases adiponectin levels and improves insulin sensitivity in obese mice. J Lipid Res 2008, 49:1658-1669.

25. Peterson SJ, Kim DH, Li M, Positano V, Vanella L, Rodella LF, Piccolomini F, Puri N, Gastaldelli A, Kusmic C, L'Abbate A, Abraham NG: The L-4F mimetic peptide prevents insulin resistance through increased levels of HO-1, PAMPK, and pAKT in obese mice. J Lipid Res 2009, 50:1293-1304.

26. Hardie DG: Minireview: the AMP-activated protein kinase cascade: the key sensor of cellular energy status. Endocrinology 2003, 144:5179-5183.

27. Hopkins TA, Ouchi N, Shibata R, Walsh K: Adiponectin actions in the cardiovascular system. Cardiovasc Res 2007, 74:11-18. 
28. Schreyer SA, Wilson DL, LeBoeuf RC: C57BL/6 mice fed high fat diets as models for diabetes-accelerated atherosclerosis. Atherosclerosis 1998 136:17-24

29. Molnar J, Yu S, Mzhavia N, Pau C, Chereshnev I, Dansky HM: Diabetes induces endothelial dysfunction but does not increase neointimal formation in high-fat diet fed C57BL/6J mice. Circ Res 2005, 96:1178-1184.

30. Surwit RS, Kuhn CM, Cochrane C, McCubbin JA, Feinglos MN: Diet-induced type II diabetes in C57BL/6J mice. Diabetes 1988, 37:1163-1167.

31. L'Abbate A, Neglia D, Vecoli C, Novelli M, Ottaviano V, Baldi S, Barsacchi R, Paolicchi A, Masiello P, Drummond GS, McClung JA, Abraham NG: Beneficial effect of heme oxygenase- 1 expression on myocardial ischemia-reperfusion involves an increase in adiponectin in mildly diabetic rats. Am J Physiol Heart Circ Physiol 2007, 293:H3532-H3541.

32. Paolocci N, Biondi R, Bettini M, Lee Cl, Berlowitz CO, Rossi R, Xia Y, Ambrosio G, L'Abbate A, Kass DA, Zweier JL: Oxygen radical-mediated reduction in basal and agonist-evoked NO release in isolated rat heart. $J$ Mol Cell Cardiol 2001, 33:671-679.

33. Sodhi K, Inoue K, Gotlinger K, Canestraro M, Vanella L, Kim DH, Manthati VL, Koduru SR, Falck JR, Schwartzman ML, Abraham NG: Epoxyeicosatrienoic acid agonist rescues the metabolic syndrome phenotype of HO-2-null mice. J Pharmacol Exp Ther 2009, 331:906-916.

34. Lara-Castro C, Luo N, Wallace P, Klein RL, Garvey WT: Adiponectin multimeric complexes and the metabolic syndrome trait cluster. Diabetes 2006, 55:249-259.

35. Sardana MK, Kappas A: Dual control mechanism for heme oxygenase: tin (IV)-protoporphyrin potently inhibits enzyme activity while markedly increasing content of enzyme protein in liver. Proc Natl Acad Sci USA 1987, 84:2464-2468.

36. Dobrian AD, Davies MJ, Prewitt RL, Lauterio TJ: Development of hypertension in a rat model of diet-induced obesity. Hypertension 2000, 35:1009-1015.

37. Dobrian AD, Davies MJ, Schriver SD, Lauterio TJ, Prewitt RL: Oxidative stress in a rat model of obesity-induced hypertension. Hypertension 2001, 37:554-560.

38. Bing OH, Brooks WW, Robinson KG, Slawsky MT, Hayes JA, Litwin SE, Sen S, Conrad $\mathrm{CH}$ : The spontaneously hypertensive rat as a model of the transition from compensated left ventricular hypertrophy to failure. $J$ Mol Cell Cardiol 1995, 27:383-396.

39. Kruger AL, Peterson S, Turkseven S, Kaminski PM, Zhang FF, Quan S, Wolin MS, Abraham NG: D-4F induces heme oxygenase-1 and extracellular superoxide dismutase, decreases endothelial cell sloughing, and improves vascular reactivity in rat model of diabetes. Circulation 2005, 111:3126-3134.

40. Dunlay SM, Weston SA, Redfield MM, Killian JM, Roger VL: Tumor necrosis factor-alpha and mortality in heart failure: a community study. Circulation 2008, 118:625-631.

41. Satoh M, Minami Y, Takahashi Y, Nakamura M: Immune modulation: role of the inflammatory cytokine cascade in the failing human heart. Curr Heart Fail Rep 2008, 5:69-74.

42. Li Volti G, Seta F, Schwartzman ML, Nasjletti A, Abraham NG: Heme oxygenase attenuates angiotensin II-mediated increase in cyclooxygenase- 2 activity in human femoral endothelial cells. Hypertension 2003, 41:715-719.

43. Kwak JY, Takeshige $K$, Cheung BS, Minakami S: Bilirubin inhibits the activation of superoxide-producing NADPH oxidase in a neutrophil cellfree system. Biochim Biophys Acta 1991, 1076:369-373.

44. Turkseven S, Kruger A, Mingone CJ, Kaminski P, Inaba M, Rodella LF, Ikehara S, Wolin MS, Abraham NG: Antioxidant mechanism of heme oxygenase- 1 involves an increase in superoxide dismutase and catalase in experimental diabetes. Am J Physiol Heart Circ Physiol 2005, 289 H701-H707.

45. Erdei N, Toth A, Pasztor ET, Papp Z, Edes I, Koller A, Bagi Z: High-fat dietinduced reduction in nitric oxide-dependent arteriolar dilation in rats: role of xanthine oxidase-derived superoxide anion. Am J Physiol Heart Circ Physiol 2006, 291:H2107-H2115.

46. Roberts CK, Barnard RJ, Sindhu RK, Jurczak M, Ehdaie A, Vaziri ND: Oxidative stress and dysregulation of $\mathrm{NAD}(\mathrm{P}) \mathrm{H}$ oxidase and antioxidant enzymes in diet-induced metabolic syndrome. Metabolism 2006, 55:928-934.

47. Galili O, Versari D, Sattler KJ, Olson ML, Mannheim D, McConnell JP, Chade AR, Lerman LO, Lerman A: Early experimental obesity is associated with coronary endothelial dysfunction and oxidative stress. Am J Physiol Heart Circ Physiol 2007, 292:H904-H911.

48. Mathew AV, Okada S, Sharma K: Obesity related kidney disease. Curr Diabetes Rev 2011, 7:41-49.

49. Ix JH, Sharma K: Mechanisms linking obesity, chronic kidney disease, and fatty liver disease: the roles of fetuin-A, adiponectin, and AMPK. J Am Soc Nephrol 2010, 21:406-412

50. Ran J, Xiong X, Liu W, Guo S, Li Q, Zhang R, Lao G: Increased plasma adiponectin closely associates with vascular endothelial dysfunction in type 2 diabetic patients with diabetic nephropathy. Diabetes Res Clin Pract 2010, 88:177-183.

51. Sambuceti G, Morbelli S, Vanella L, Kusmic C, Marini C, Massollo M, Augeri C, Corselli M, Ghersi C, Chiavarina B, Rodella LF, L'Abbate A, Drummond G, Abraham NG, Frassoni F: Diabetes Impairs the Vascular Recruitment of Normal Stem Cells by Oxidant Damage; Reversed by Increases in PAMPK, Heme Oxygenase-1 and Adiponectin. Stem Cells 2009, 27:399-407.

52. Merrill GF, Kurth EJ, Hardie DG, Winder WW: AICA riboside increases AMPactivated protein kinase, fatty acid oxidation, and glucose uptake in rat muscle. Am J Physiol 1997, 273:E1107-E1112.

53. Kudo N, Gillespie JG, Kung L, Witters LA, Schulz R, Clanachan AS, Lopaschuk GD: Characterization of 5'AMP-activated protein kinase activity in the heart and its role in inhibiting acetyl-CoA carboxylase during reperfusion following ischemia. Biochim Biophys Acta 1996, 1301:67-75.

54. Terai K, Hiramoto Y, Masaki M, Sugiyama S, Kuroda T, Hori M, Kawase I, Hirota H: AMP-activated protein kinase protects cardiomyocytes against hypoxic injury through attenuation of endoplasmic reticulum stress. $\mathrm{Mol}$ Cell Biol 2005, 25:9554-9575

55. Schulz E, Dopheide J, Schuhmacher S, Thomas SR, Chen K, Daiber A, Wenzel P, Munzel T, Keaney JF Jr: Suppression of the JNK pathway by induction of a metabolic stress response prevents vascular injury and dysfunction. Circulation 2008, 118:1347-1357.

56. Dimmeler S, Fleming I, Fisslthaler B, Hermann C, Busse R, Zeiher AM: Activation of nitric oxide synthase in endothelial cells by Akt-dependent phosphorylation. Nature 1999, 399:601-605.

57. Chen ZP, Mitchelhill Kl, Michell BJ, Stapleton D, Rodriguez-Crespo I, Witters LA, Power DA, Ortiz De Montellano PR, Kemp BE: AMP-activated protein kinase phosphorylation of endothelial NO synthase. FEBS Lett 1999, 443:285-289.

doi:10.1186/1758-5996-3-37

Cite this article as: Cao et al.: High fat diet enhances cardiac abnormalities in SHR rats: Protective role of heme oxygenaseadiponectin axis. Diabetology \& Metabolic Syndrome 2011 3:37.

\section{Submit your next manuscript to BioMed Central and take full advantage of:}

- Convenient online submission

- Thorough peer review

- No space constraints or color figure charges

- Immediate publication on acceptance

- Inclusion in PubMed, CAS, Scopus and Google Scholar

- Research which is freely available for redistribution

Submit your manuscript at www.biomedcentral.com/submit
C Biomed Central 